\begin{tabular}{|c|c|c|c|c|c|c|c|c|c|c|c|}
\hline \multirow[b]{3}{*}{$\begin{array}{l}\text { Age } \\
\text { group }\end{array}$} & \multirow[b]{3}{*}{ BMI group } & \multicolumn{5}{|c|}{ Male } & \multicolumn{5}{|c|}{ Female } \\
\hline & & \multicolumn{2}{|c|}{ Steroid-exposed } & \multicolumn{2}{|c|}{ Never exposed } & \multirow[b]{2}{*}{$p$-value } & \multicolumn{2}{|c|}{ Steroid-exposed } & \multicolumn{2}{|c|}{ Never exposed } & \multirow[b]{2}{*}{$p$-value } \\
\hline & & Patients & $\begin{array}{l}\text { Absolute rate (per } \\
1,000 \text { patient years) }\end{array}$ & Patients & $\begin{array}{l}\text { Absolute rate (per } \\
1,000 \text { patient years) }\end{array}$ & & Patients & $\begin{array}{l}\text { Absolute rate (per } \\
1,000 \text { patient years) }\end{array}$ & Patients & $\begin{array}{l}\text { Absolute rate (per } \\
1,000 \text { patient years) }\end{array}$ & \\
\hline \multirow[t]{4}{*}{$18-42$} & 1: Underweight & 1,242 & 2.0 & 1,195 & 0.0 & 0.5661 & 3,079 & 4.5 & 3,486 & 0.9 & 0.1361 \\
\hline & 2: Normal & 18,798 & 2.2 & 19,638 & 0.0 & $<0.0001$ & 42,234 & 0.9 & 47,340 & 0.1 & 0.0049 \\
\hline & 3: Overweight & 16,536 & 2.6 & 15,114 & 0.0 & 0.0001 & 24,893 & 0.5 & 24,009 & 0.1 & 0.2382 \\
\hline & 4: Obese + & 10,311 & 0.6 & 8,453 & 0.0 & 0.2874 & 26,600 & 0.6 & 20,320 & 0.3 & 0.4614 \\
\hline \multirow[t]{4}{*}{$43-67$} & 1: Underweight & 1,254 & 27.4 & 683 & 0.0 & 0.0040 & 2,420 & 30.9 & 1,990 & 18.5 & 0.1141 \\
\hline & 2: Normal & 27,037 & 8.6 & 26,569 & 2.0 & $<0.0001$ & 45,467 & 15.9 & 50,423 & 6.1 & $<0.0001$ \\
\hline & 3: Overweight & 42,428 & 4.3 & 43,872 & 0.7 & $<0.0001$ & 42,620 & 10.8 & 43,253 & 4.1 & $<0.0001$ \\
\hline & 4: Obese + & 31,478 & 2.5 & 30,852 & 0.8 & 0.0007 & 45,339 & 6.0 & 39,876 & 2.4 & $<0.0001$ \\
\hline \multirow[t]{4}{*}{$68-92$} & 1: Underweight & 936 & 30.3 & 432 & 10.3 & 0.1505 & 1,532 & 70.9 & 1,239 & 26.6 & 0.0003 \\
\hline & 2: Normal & 15,891 & 11.3 & 15,021 & 4.5 & $<0.0001$ & 18,308 & 42.3 & 18,717 & 18.6 & $<0.0001$ \\
\hline & 3: Overweight & 21,371 & 7.3 & 23,137 & 1.8 & $<0.0001$ & 19,149 & 26.2 & 19,760 & 12.9 & $<0.0001$ \\
\hline & 4: Obese + & 11,216 & 5.6 & 11,396 & 1.9 & 0.0021 & 14,453 & 20.0 & 13,614 & 8.7 & $<0.0001$ \\
\hline
\end{tabular}

Disclosure of Interests: Ellen Berni Consultant of: Employed by Pharmatelligence, which carries out consultancy work for AstraZeneca and other pharmaceutical companies., Philip Ambery Shareholder of: AstraZeneca, Employee of:AstraZeneca, Samuel Adamsson Eryd Shareholder of:AstraZeneca, Employee of: AstraZeneca, Sara Jenkins-Jones Consultant of: Employed by Pharmatelligence, which carries out consultancy work for AstraZeneca and other pharmaceutical companies., Mary Brown Shareholder of: AstraZeneca, Employee of: AstraZeneca, Carol Astbury Shareholder of: AstraZeneca, Employee of: AstraZeneca, Phillip Hunt Shareholder of: AstraZeneca, Employee of: AstraZeneca, Craig Currie Consultant of: Director of Pharmatelligence, which carries out consultancy work for AstraZeneca and other pharmaceutical companies

DOI: 10.1136/annrheumdis-2021-eular.2424

\section{POS1433 IMPACT OF RHEUMATOID ARTHRITIS ON STRESS: A SYSTEMATIC SCOPING REVIEW}

C. Vervloesem ${ }^{1}$, D. De Cock $^{1}$, A. Van Breda ${ }^{1}$, D. Bertrand ${ }^{1}$, M. Doumen $^{1,2}$, S. Pazmino ${ }^{1}$, R. Westhovens ${ }^{1,2}$, P. Verschueren ${ }^{1,2} .{ }^{1} K U$ Leuven, Skeletal Biology and Engineering Research Centre, Leuven, Belgium; ${ }^{2}$ University Hospitals Leuven, Rheumatology, Leuven, Belgium

Background: The literature about the impact of Rheumatoid Arthritis (RA) on mental health is mostly focused on depression and anxiety. Yet, patients can experience stress without depressed mood or anxiety.

Objectives: To examine the impact of RA on psychological stress excluding depression and anxiety focusing on 3 questions: 1 ) What is the stress level of RA patients compared to a control group? 2) Which types of stress do RA patients experience? 3) Which are risk factors to develop stress as an RA patient? Methods: Four scientific databases, EMBASE, PubMed (including MEDLINE), Web of Science Core Collection and Cochrane Library, were systematically

Table 1. Included Studies

\begin{tabular}{|c|c|c|c|c|c|c|}
\hline $\begin{array}{l}\text { First } \\
\text { Author }\end{array}$ & Year & Country & Population & $\begin{array}{c}\text { Age } \\
\text { Mean } \pm \text { SD }\end{array}$ & $\begin{array}{c}\text { Stress } \\
\text { Instrument }\end{array}$ & $\begin{array}{c}\text { Quality } \\
\text { Assessment }\end{array}$ \\
\hline Bugajska & 2010 & Poland & $\begin{array}{l}\text { N=437 Polish } \\
\text { N=137 German }\end{array}$ & $\begin{array}{l}>50 y(71 \%) \\
>50 y(38 \%)\end{array}$ & SF36v2 & AXIS: $16 / 20$ \\
\hline Coty & 2017 & USA & $\mathrm{N}=80$ & $54 y \pm 12 y$ & RCQW & AXIS: $17 / 20$ \\
\hline Cunha & 2016 & Portugal & $\mathrm{N}=80$ & $58 y$ & DASS-21 & AXIS: 10/20 \\
\hline Goulia & 2015 & Greece & $N=168$ & $55 y \pm 13 y$ & SCL-90R & MINORS: 11/16 \\
\hline Latman & 1996 & USA & $\begin{array}{c}\mathrm{RA}, \mathrm{N}=128 \\
\mathrm{OA}, \mathrm{N}=79\end{array}$ & $\begin{array}{l}56 y \\
63 y\end{array}$ & SRRS & AXIS: 20/20 \\
\hline Mancuso & 2006 & USA & $\begin{array}{l}\mathrm{RA}, \mathrm{N}=122 \\
\mathrm{HC}, \mathrm{N}=122\end{array}$ & $\begin{array}{l}49 y \pm 12 y \\
49 y \pm 12 y\end{array}$ & DUSOCS & MINORS: $20 / 24$ \\
\hline Nyklicek & 2015 & $\begin{array}{l}\text { The } \\
\text { Netherlands }\end{array}$ & $\mathrm{N}=201$ & $57 y \pm 12 y$ & PSS & MINORS: 13/16 \\
\hline Persson & 2005 & Sweden & $\mathrm{N}=158$ & $52 y$ & SCL-90R & MINORS: $12 / 16$ \\
\hline Rahim & 2018 & Malaysia & $\mathrm{N}=189$ & $52 y \pm 11 y$ & DASS-21 & AXIS: 17/20 \\
\hline Rice & 2017 & Canada & $\begin{array}{l}R A, N=226 \\
C P, N=229\end{array}$ & $\begin{array}{l}58 y \pm 15 y \\
45 y \pm 12 y\end{array}$ & DASS-21 & AXIS: $17 / 20$ \\
\hline Rice & 2016 & Canada & $\begin{array}{l}R A, N=163 \\
C P, N=167\end{array}$ & $\begin{array}{l}56 y \pm 13 y \\
45 y \pm 11 y\end{array}$ & DASS-21 & AXIS: $18 / 20$ \\
\hline Richter & 2018 & Germany & $\begin{array}{l}\mathrm{RA}, \mathrm{N}=163 \\
\mathrm{HC}, \mathrm{N}=167\end{array}$ & $\begin{array}{l}48 y \pm 10 y \\
43 y \pm 10 y\end{array}$ & ERI & AXIS: 17/20 \\
\hline Smith & 2002 & USA & $\begin{array}{l}R A, N=93 \\
O A, N=82 \\
H C, N=80\end{array}$ & $\begin{array}{l}\text { RA, 62y } \\
\mathrm{OA}, 65 \mathrm{y} \\
\mathrm{HC}, 62 \mathrm{y}\end{array}$ & $\begin{array}{c}1 \text { question } \\
\text { probing } \\
\text { stress }\end{array}$ & MINORS: 17/24 \\
\hline Treharne & 2007 & UK & $\mathrm{N}=134$ & $55 y$ & PSS & MINORS: 11/16 \\
\hline $\begin{array}{l}\text { Turner- } \\
\text { Cobb }\end{array}$ & 1998 & UK & $\begin{array}{l}R A, N=13 \\
C P, N=24\end{array}$ & $\begin{array}{l}42 y \pm 8 y \\
39 y \pm 4 y\end{array}$ & LEI/HUS & MINORS: $17 / 24$ \\
\hline Zautra & 1997 & USA & $\mathrm{N}=41$ & $55 y \pm 10 y$ & ISLE & MINORS: 12/16 \\
\hline
\end{tabular}

searched from inception until 19/04/2020. Eligible studies included psychological stress in RA patients as outcome. Two reviewers (CV\&AVB) independently screened titles and abstracts, and later full texts for eligibility. Full-text screening excluded studies without a separate RA population, with a focus on only anxiety and/or depression or not answering at least $1 / 3$ research questions. Quality was appraised by MINORS/AXIS tools.

Results: From 11115 potentially relevant studies, 16 studies met the inclusion criteria (Table 1). Remarkably, 13 different stress measurement instruments were picked-up in this review. Work stress and interpersonal stress seem more prevalent in RA patients compared to healthy controls. Stress at disease onset was more prevalent in RA compared to osteoarthritis. Psychological stress was higher in patients with chronic pain compared to RA. Role stress, social stress and work stress were induced by RA. More disability, more pain, less social support, lower income, younger age and personality factors like excessive worrying, pessimism, and sensitivity to anxiety, seem to increase the risk for increased stress levels.

Conclusion: This scoping review is to our knowledge the first to address the heterogeneity of measurement tools and definitions of stress in RA research. It provides the basis for further research, which is needed to predict different stress trajectories and respond to these with patient-centered interventions. Disclosure of Interests: None declared

DOI: 10.1136/annrheumdis-2021-eular.2702

\section{POS1434 WHICH PROGNOSTIC FACTORS MIGHT PREDICT THE NEED FOR TREATMENT ADAPTATION IN EARLY RHEUMATOID ARTHRITIS? A COMPARISON OF MACHINE LEARNING, SURVIVAL ANALYSIS AND REGRESSION METHODS}

G. Verhavert ${ }^{1,2}$, T. Verdonck ${ }^{2}$, S. Pazmino ${ }^{1}$, V. Stouten ${ }^{1}$, D. Bertrand ${ }^{1}$, M. Doumen ${ }^{1}$, R. Westhovens ${ }^{1,3}$, P. Verschueren ${ }^{1,3}$, D. De Cock ${ }^{1}{ }^{1} K U$ Leuven, Skeletal Biology and Engineering Research Center, Leuven, Belgium; ${ }^{2} \mathrm{KU}$ Leuven, Department of Mathematics, Leuven, Belgium; ${ }^{3}$ University Hospitals Leuven, Rheumatology, Leuven, Belgium

Background: Current EULAR guidelines recommend treating RA early, intensively and to-target. A data-driven tool for planning the optimal moment for subsequent visits might adapt visit schedules more to the patient's needs, without losing treatment quality.

Objectives: To determine the optimal statistical model and clinical factors to predict the time to a treatment adaptation in early RA patients.

Methods: This study included 379 patients from the treat-to-target Care in Rheumatoid Arthritis (CareRA) trial. The CareRA protocol included 2 predefined treatment adaptation steps for patients not reaching low disease activity (DAS28CRP $<3.2$. . The 1 st adaptation was an MTX dose increase and the second one was adding/increasing the dose of a 2nd csDMARD. Three predictive models (Cox Proportional Hazards, Linear Multi-Task Regression and Random Survival Forest) were trained and validated to predicting time until these 2 adaptations. Factor selection for these models was performed by applying Cox Proportional Hazards with LASSO penalty to each set of demographic and clinical variables recorded at baseline, w4 and w8. Models used these factors at these 3 time points to predict future treatment adaptations. Model performance was estimated by the Uno Concordance Index with five-fold cross-validation. Missing data were imputed by interpolation or mean score.

Results: Factors selected to predict the first per protocol change included TJC, SJC, HAQ, CRP, pain and morning stiffness $>15 \mathrm{~min}$. Factors selected to predict the second per protocol change included TJC, SJC, PGA, PhGA. Uno Concordance indices showed similar scores per different statistical model but higher scores at w4 and w8 compared to baseline indicating a better predictive performance (Table 1. next page). 